\title{
Processamento dos afixos do PB: o reconhecimento de morfemas por crianças não alfabetizadas e em processo de alfabetização
}

\section{Processing of BP affixes: the recognition of morphemes by illiterate children and children in literacy process}

\author{
Veridiana P. Borges ${ }^{1}$, Gabriela Tornquist Mazzaferro², Carmen Lúcia Barreto Matzenauer ${ }^{3}$
}

Mestre em Linguística Aplicada - UCPEL Universidade Católica de Pelotas. Programa de Pós-Graduação em Letras. E-mail: veridgj@gmail.com

Doutoranda em Linguística Aplicada - UCPEL Universidade Católica de Pelotas. Prog Pós-Graduação em Letras. - PUCRS Pontificia Universidade Católica do Rio Grande do Sul. Professora titular do Programa de PósGraduação em Letras - UCPEL Catolica de
RESUM0: Este artigo discute como se dá o processamento de pseudopalavras formadas por um morfema-base e por afixos em crianças não alfabetizadas e em crianças que estão em processo de alfabetização, falantes nativas do Português Brasileiro (PB), por meio da aplicação da Tarefa de Reconhecimento de Pseudovocábulos, que avalia a capacidade de a criança reconhecer e processar os afixos do PB e verificar a interpretação do significado que cada afixo veicula ao juntar-se ao morfema lexical. A atividade foi composta por pseudopalavras que, em sua constituição, mostram afixos pertencentes ao PB; a combinação do morfema-base com o afixo deriva palavra não dicionarizada que poderia pertencer ao léxico da língua (ex.: descruel). Para tanto, foram contadas histórias aos sujeitos e, posteriormente, foram feitas perguntas relacionadas às pseudopalavras. 0 corpus foi constituído por dados de dezesseis crianças monolíngues, subdivididas em quatro faixas etárias. Os resultados apontaram que a maioria dos informantes interpretou o significado dos pseudovocábulos, indicando a capacidade que as crianças têm de refletir sobre a função e o significado dos morfemas. Os dados foram analisados com base em concepções teóricas da Aquisição da Linguagem, da Aquisição da Morfologia e da Consciência Morfológica (BORGES, 2015; SEIXAS, 2007; LIMA, 2006, LORANDI, 2006).

Palavras-chave: Consciência morfológica; Processamento morfológico; Reconhecimento de afixos; Tarefas de reconhecimento; Aquisição da linguagem.

ABSTRACT: This paper discuss how it occurs the processing of pseudo-words formed by a base morpheme and by affixes in non-literate children and in children who are in the process of literacy, Brazilian Portuguese (BP) native speakers, through the application of the Pseudo-vocabulary Recognition Task, which evaluates the child's ability to recognize and process BP affixes and to verify the interpretation of the meaning that each affix conveys when joining the lexical morpheme. The activity was composed of pseudo-words that, in their constitution, show affixes that belong to $\mathrm{BP}$; the combination of the base morpheme with the affix derives word which is not in a dictionary that could belong to the lexicon of the language (eg, "descruel"). For that, stories were told to the subjects and, later, questions related to the pseudo-words were asked. The corpus consisted of data of sixteen monolingual children, subdivided into four age groups. The results showed that most informants interpreted the meaning of the pseudo-words, indicating the ability of children to reflect on the function and meaning of morphemes. The data were analyzed based on theoretical conceptions of Language Acquisition, Morphology Acquisition and Morphological Consciousness (BORGES, 2015; SEIXAS, 2007; LIMA, 2006, LORANDI, 2006).

Keywords: Morphological awareness; Morphological processing; Recognition of affixes; Recognition tasks; Language acquisition. 


\section{Introdução}

$\mathrm{D}$ iante da grande escassez de estudos que tenham como foco os processos de aquisição do componente morfológico da língua e, principalmente, que tenham interesse na forma como se dá o reconhecimento e o processamento dos afixos do Português Brasileiro (PB) pela criança, a presente investigação, que é um recorte de um estudo mais amplo (BORGES, 2015), teve como objetivo verificar o desenvolvimento da Consciência Morfológica, observando, de modo mais específico, como se dá o processamento da morfologia de pseudopalavras em crianças não alfabetizadas e em crianças em processo de alfabetização.

Com a aplicação de uma tarefa, denominada Tarefa de Reconhecimento de Pseudovocábulos, buscamos avaliar a capacidade de a criança reconhecer, processar e depreender afixos do $\mathrm{PB}$, bem como verificar a interpretação do significado que cada afixo veicula ao juntar-se ao morfema lexical. Integraram essa tarefa os sufixos agentivos -eiro, -ista, -or, e os prefixos dese re-. O corpus foi constituído por dados coletados junto a dezesseis crianças monolíngues, falantes nativas do PB, com idade entre 4 e 7 anos, divididas em quatro faixas etárias.

A análise dos resultados teve o suporte teórico das áreas da Aquisição da Linguagem, da Aquisição da Morfologia, da Morfologia e da Consciência Morfológica (BORGES, 2015; SEIXAS, 2007; LIMA, 2006). Com esse centro de interesse, a presente pesquisa alia-se aos estudos que se ocupam do desenvolvimento da Consciência Morfológica no âmbito da Aquisição da Linguagem.

\section{Aporte Teórico}

\subsection{Sobre a aquisição da Morfologia e da Consciência Morfológica \\ - uma revisão}

O processo de aquisição da Morfologia implica a incorporação, à gramática da criança, das unidades morfológicas da língua. Indo além da simples presença de morfemas no sistema linguístico da criança, a Consciência Morfológica implica a sensibilidade a morfemas, evidenciando a habilidade de a criança lidar com tais unidades linguísticas e refletir sobre elas.

A literatura da área da Aquisição da Linguagem registra um número muito restrito de pesquisas que abordem o desenvolvimento da Consciência Morfológica. Entre os estudos que têm como foco o PB, destacamos Figueira (1999), Lorandi (2006) e Lima (2006). Todos os estudos evidenciam a precocidade, nas crianças, de manifestações linguísticas com fenômenos da morfologia da língua, mas também mostram uma gradação no processo de desenvolvimento morfológico, bem como da consciência desse componente da gramática da língua.

O foco da pesquisa de Figueira (1999) foi a aquisição de uma classe verbal do português que explicita ações reversas, como, por exemplo, "liga a televisão por desliga a televisão". Os resultados revelaram que uma única forma gramatical assume duas funções na fala das crianças em fase muito precoce da aquisição. A investigadora observou que a marca gramatical em consonância com o alvo vai surgindo a partir da própria experiência da criança com a linguagem. O estudo revelou que as crianças apresentaram ocorrência da reversão por meio do prefixo por volta dos 3;10 (anos; meses).

Lorandi (2006) investigou o processo de regularização morfológica aplicado a formas verbais irregulares. A autora verificou que crianças com 
idades entre 2 e 3 anos já produzem formas morfológicas em consonância com o alvo, mas ainda em variação com formas regularizadas.

O estudo de Lima (2006) teve como objetivo verificar o modo como se dá a aquisição de diferentes morfemas, incluindo prefixos e sufixos, sendo que alguns se identificam com os focalizados no presente estudo. Os dados, obtidos junto a crianças com idade entre 2 e 7 anos, indicaram que a ordem de aquisição da morfologia derivacional, prefixos e sufixos, e de compostos apresentou um aumento expressivo nas primeiras faixas etárias, enquanto os compostos apresentaram um avanço moderado no uso, fato evidenciado em todas as faixas etárias. Além disso, os prefixos, sufixos e compostos adquiridos pelas crianças mostraram relação com o input que recebem de seus cuidadores durante o processo de interlocução. Os resultados também mostraram que os únicos prefixos encontrados na fala das crianças foram des- e re-. Quanto aos sufixos, o mais recorrente é o morfema -inho/zinho, indicando grau diminutivo. Já os compostos que mais aparecem na fala das crianças são os formados por $\mathrm{V}+\mathrm{N}$ (verbo + nome), $\mathrm{N}+\mathrm{p}+\mathrm{N}$ (nome + preposição + nome) e $\mathrm{N}+\mathrm{A}$ (nome + adjetivo). Os resultados do estudo de Lima indicaram que os afixos e compostos mais utilizados pelas crianças são aqueles mais produtivos no PB.

\subsection{Particularmente sobre a Consciência Morfológica}

A literatura da área concebe como Consciência Morfológica a capacidade que a criança tem de refletir sobre os morfemas da língua. Os estudos sobre o desenvolvimento dessa competência dividem-se em dois diferentes tipos, dependendo da natureza da unidade estrutural que focaliza. Nesse sentido, a Consciência da Morfologia Flexional têm como foco a investigação da capacidade que as crianças possuem de identificar morfemas flexionais, ou seja, as flexões de gênero e número dos nomes (substantivos, adjetivos), bem como as flexões de número-pessoa e de modo-tempo dos verbos; diferentemente, os estudos da Consciência da Morfologia Derivacional, centrando-se nos morfemas derivacionais, ocupam-se do processo de formação de palavras que ocorre pelo aditamento de prefixos e de sufixos a um morfema-base. Além disso, com foco no processo derivacional, também investigam a decomposição das palavras, ou seja, a competência que a criança tem de decompor palavras derivadas e, assim, chegar à palavra primitiva.

De acordo com Seixas (2007), "a Consciência Morfológica faz parte da Consciência Metalinguística; implica reflexão sobre a língua e o seu uso e também capacidades de planejamento". Tendo em vista que a metalinguagem é uma habilidade própria do sujeito, utilizada quando ele fala sobre o seu próprio sistema, requer que as propriedades da língua já sejam conhecidas por ele a fim de que seja capaz de observar os componentes que formam uma palavra, analisando-os e reconhecendo os seus significados.

Conforme Valtin (1984) apud Carlisle (1995), há três estágios do conhecimento linguístico: $1^{\stackrel{0}{0})}$ conhecimento inconsciente ou o uso automático da linguagem; $2^{\circ}$ ) conhecimento concreto ou presente; e $3^{\circ}$ ) conhecimento consciente. Essa perspectiva indica que a criança começa a identificar as regras morfológicas entre os 6 e 7 anos de idade e que isso acontece de forma gradual.

Outra perspectiva teórica, proposta por Morais (1991) apud Carlisle e Nomanbhoy (1993), defende que o desenvolvimento da Consciência Morfológica depende de aspectos fonológicos para emergir. Segundo Seixas (2007, p. 18), à medida que as crianças tomam conhecimento inicialmente das sílabas e depois dos fonemas, torna-se possível um subsequente tipo de aprendizagem, a morfológica. Esta envolve o uso de uma análise fonológica mais complexa, de forma a apreender o papel semântico decorrente da sintaxe dos morfemas. Num terceiro nível, em que a fonologia se encontra mais avançada, está assegurada a aprendizagem de regras morfofonológicas que caracterizam a formação de muitas palavras derivadas. Com base nessas 
afirmações, a Fonologia apresenta relação com a aprendizagem morfológica, bem como com o desenvolvimento da Consciência Morfológica, apontando uma interação entre esses componentes da língua.

A literatura evidencia que não há concordância, por parte dos pesquisadores, quanto ao período em que se dá a emergência da Consciência Morfológica nas crianças, bem como quanto à sua relação com o processo de leitura e, inclusive, com o desenvolvimento fonológico (SEIXAS, 2007). Estudos como os de Bryant, Devine, Ledward e Nunes, 1997; Bryant, Nunes e Aidinis, 1999; Bryant e Nunes, 2003; Carlisle, 1988, 1995, 2000; Machado, 2011; Nunes, 1998; Nunes, Bryant \& Bindman 1997a, b, c; Rubin, 1988; e, Rosa, 2003, que analisaram crianças com idades compreendidas entre os 4 e os 16 anos, corroboram estes resultados.

Alguns autores, como Tunmer, Nesdale e Wright (1987) referidos em Melo (2002), indicam que a emergência da Consciência Morfológica está condicionada à exposição da criança ao processo de alfabetização e que, por isso, se manifesta entre os 4 e 8 anos; outros apontam que esse processo ocorre mais tardiamente. Considerando as diferentes posições, Carlisle (1995) entende que a Consciência Morfológica precisa ser mais amplamente explorada, uma vez que ainda não está bem delimitado se o desenvolvimento dessa habilidade ocorre durante a exposição da criança aos processos de leitura e de escrita ou se aflora antes de essas crianças estarem expostas ao processo de alfabetização.

O processo de avaliação da Consciência Morfológica dá-se por meio do cumprimento de tarefas que têm como objetivo medir o desempenho das crianças em circunstâncias que necessitam de uma reflexão sobre o significado das palavras, bem como a capacidade que as crianças possuem de identificar e manipular os morfemas da língua. Essa habilidade é avaliada por meio de tarefas específicas, que exigem diferentes níveis de desempenho.
Com o intuito de caracterizar com clareza o encaminhamento do processo de avaliação da Consciência Morfológica utilizados neste trabalho, expomos a Tarefa de Interpretação de Pseudopalavras (MACHADO, 2011). A atividade objetiva verificar a capacidade das crianças relativa ao reconhecimento e à interpretação dos morfemas da língua. Nessa tarefa unem-se, a um morfema-base, prefixos e/ou sufixos que pertencem à língua, porém essa formação irá dar origem a um vocábulo não existente no léxico, ou seja, a uma pseudopalavra.

\section{Aspectos metodológicos}

\subsection{Caraterização dos informantes}

Para este trabalho, foram utilizados dados de 16 crianças brasileiras (8 meninos e 8 meninas), monolíngues, falantes nativas do PB, com idades entre 4 e 7 anos, residentes na cidade de Pelotas-RS. As crianças foram separadas por faixas etárias (FE) e por sexo, somando-se quatro crianças em cada faixa etária: FE1: crianças com 4 anos de idade; FE 2: crianças com 5 anos de idade; FE 3: crianças com 6 anos de idade; FE 4: crianças com 7 anos de idade. Cada FE foi integrada por 2 meninos e 2 meninas. 0 presente estudo obteve a aprovação do Comitê de Ética da Universidade Católica de Pelotas, sob o protocolo no $\mathbf{4} 3687915.8 .0000 .5339$.

Como o objetivo deste trabalho foi verificar a emergência da Consciência Morfológica, observando, particularmente, como se dá o processamento de pseudopalavras em crianças não alfabetizadas e em crianças em processo de alfabetização, os informantes foram divididos em dois grupos: (a) Grupo I - crianças não alfabetizadas - que correspondem às faixas etárias FE1 e FE2; (b) Grupo II - crianças em processo de alfabetização - que pertencem às faixas etárias FE3 e FE4. Embora a variável sexo tenha sido observada na seleção dos informantes, não foi considerada na análise dos dados. 
Foram respeitados alguns critérios para a seleção das crianças, tais como: (a) não apresentar qualquer tipo de desvio fonológico; (b) ser falante nativa do PB; (c) apresentar desenvolvimento linguístico e cognitivo condizentes com a sua idade; (d) pertencer às faixas etárias definidas nesta investigação; (e) não estar alfabetizada (idade: 4 e 5 anos, frequentando, respectivamente, o Maternal A e B); ou estar em processo de alfabetização (idade: 6 e 7 anos, frequentando, respectivamente, o $1^{\circ}$ e o $2^{\circ}$ ano do Ensino Fundamental).

As entrevistas individuais foram gravadas em gravador digital Roland - R-05, foram transcritas ortograficamente e posteriormente analisadas. A apresentação da Tarefa de Reconhecimento de Pseudovocábulos se deu de forma lúdica, por meio do uso de fantoches.

\subsection{Caraterização do Instrumento}

A Tarefa de Reconhecimento de Pseudovocábulos tem como objetivo avaliar como se dá a depreensão de afixos, bem como a interpretação do significado que cada um veicula ao reunir-se ao morfema lexical. A atividade foi composta por pseudopalavras que, em sua constituição, mostram afixos pertencentes à Língua Portuguesa; a combinação do morfema-base com o afixo deriva palavra não dicionarizada, mas que poderia pertencer ao léxico da língua (ex.: descruel). Neste estudo, foram utilizados os sufixos agentivos -or, -eiro e -ista, e os prefixos des- e re-.

Na aplicação da tarefa, foram apresentadas aos informantes pequenas histórias elaboradas especificamente para esta atividade. Para cada afixo, uma história diferente foi criada, sendo todas elas "contadas" às crianças por meio do uso de fantoches. Após a história, foi pedido a cada criança que informasse o significado de cada pseudopalavra e o que as palavras tinham em comum: esperava-se que percebessem qual era o "pedacinho" igual nas palavras apresentadas. Por fim, pediu-se que fosse identificada a posição em que os afixos se encontravam nas palavras, se prefixo ou sufixo.
A atividade foi composta por cinco histórias, a fim de avaliar o reconhecimento e o processamento de afixos da língua adjungidos a morfemasbase não existentes no $\mathrm{PB}$, ou seja, a pseudovocábulos (ex.: camisador palavra que nomeia pessoa que confecciona camisas). Em cada uma das histórias havia quatro pseudopalavras contextualizadas dentro de um pequeno texto. As palavras utilizadas nas histórias foram:

1) Sufixos or - bonecador, frutador, camisador, pipador;

2) Sufixos eiro(a) - telefoneira, futeboleiro, lavareiro, batereiro;

3) Sufixos ista - quadrista, arvorista, jardinista, moranguista;

4) Prefixo des - desfeliz, desbonito, deslegal, desbondoso;

5) Prefixo re - relatir, reamar, rechorar, redormir.

\section{Descrição e análise dos dados}

Para uma melhor apresentação dos dados obtidos na Tarefa de Reconhecimento de Pseudovocábulos, os resultados foram dispostos em quadros e, a seguir, descritos e analisados. Foi destacada a divisão das crianças em dois grupos: Grupo I - crianças não alfabetizadas (FEs 1 e 2 (4 e 5 anos de idade)); e Grupo II - crianças em processo de alfabetização (FEs 3 e 4 (6 e 7 anos de idade)). Ainda os informantes foram identificados por números que vão de 1 a 16, com a especificação (F) e (M), feminino e masculino, respectivamente.

Cada quadro registra o reconhecimento dos afixos pelos informantes de cada FE. Nos quadros, o (X) foi utilizado para identificar os pseudovocábulos reconhecidos pelos sujeitos - formados por morfema base + afixos - e a sigla $(n r)$ foi utilizada para indicar que os afixos que derivaram as pseudopalavras não foram reconhecidos. Além disso, (I) e (F) indicam a localização do afixo: no início ou no final da pseudopalavra.

A atividade apresentada no presente artigo, que procurou avaliar a interpretação do significado das pseudopalavras, a identificação da 
semelhança entre as palavras e a indicação da posição do afixo, é um recorte de um estudo mais amplo. Explica-se, assim, a ausência de dados, em todos os quadros, da Informante 5F, pertencente a FE2 - Grupo 1, visto que a menina esteve afastada da escola durante o período de aplicação da Tarefa de Reconhecimento de Pseudovocábulos. Como consequência, os quadros da FE2 apresentam uma lacuna correspondente aos dados dessa criança.

\subsection{Reconhecimento dos sufixos -or, -eiro, -ista - Grupo 1}

Os dados referentes à aplicação da Tarefa de Reconhecimento de Pseudovocábulos (Sufixos -or, -eiro, -ista) no Grupo 1 (FE1 e FE2) são apresentados no Quadro 1.

Quadro 1 - Resultados da aplicação da Tarefa de Reconhecimento Pseudovocábulos (Sufixos -or, -eiro, -ista) - Grupo 1

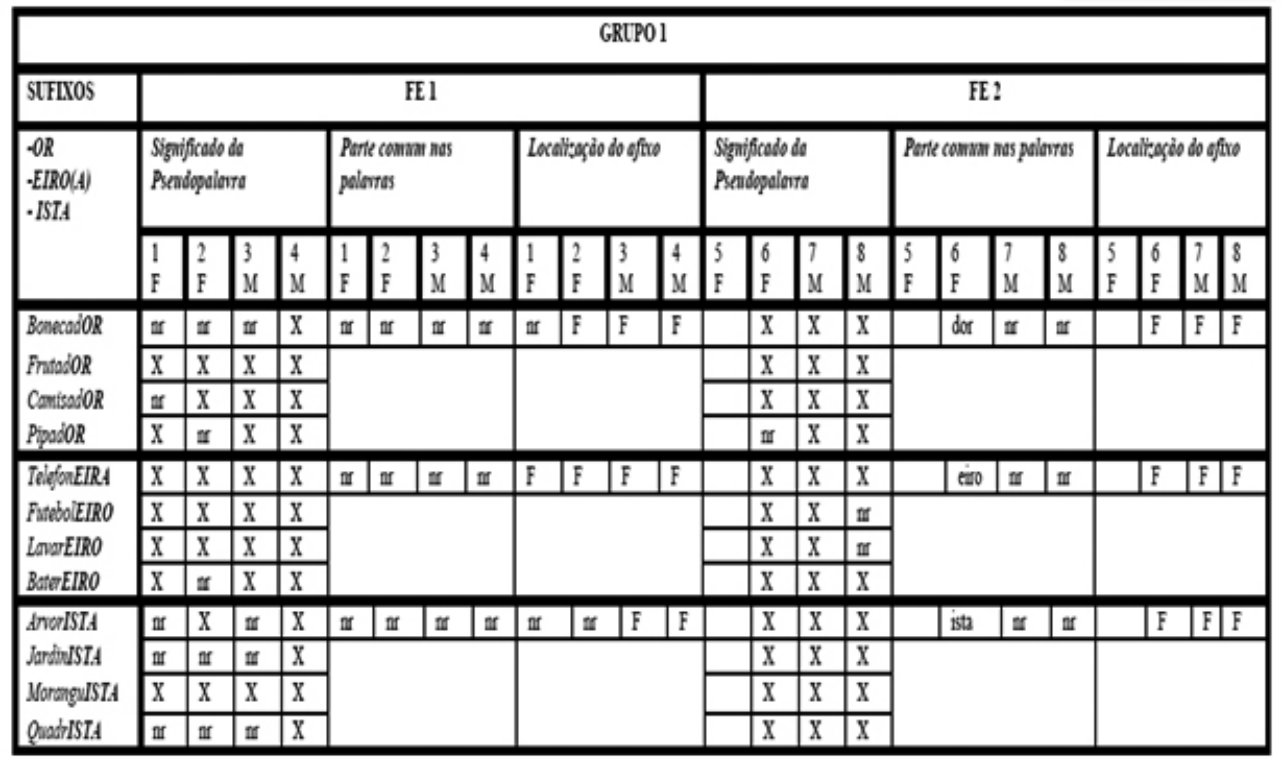

Fonte: As autoras.
De acordo com os dados do Quadro 1, as crianças do Grupo 1, em sua grande maioria, ao serem indagadas sobre o significado dos pseudovocábulos formados por um morfema lexical + sufixos, responderam à pergunta de forma satisfatória, apesar de esses vocábulos não pertencerem ao léxico do PB. Observamos, assim, que é possível o reconhecimento do significado que a palavra adquire ao ser derivada da adjunção, a um morfema-base, dos sufixos agentivos -or, -eiro e -ista.

Nas pseudopalavras formadas pelo sufixo $-o r$, num total de 28 possibilidades de reconhecimento (16 para FE1 e 12 para FE2), verificamos que as crianças reconheceram 22 das palavras inventadas e, consequentemente, apenas 6 palavras não foram reconhecidas. A respeito do sufixo -or, verificamos que a palavra bonecador (pessoa que faz, vende, fabrica bonecos), formada pelo morfema lexical + sufixo agentivo -or, foi a que se mostrou de interpretação mais difícil (não foi captada pelas crianças $1 \mathrm{~F}, 2 \mathrm{~F}$ e $3 \mathrm{M}$ ). $\mathrm{O}$ significado do vocábulo pipador (pessoa que faz, vende, fabrica, empina pipa) não foi interpretado pelas crianças $2 \mathrm{~F}$ e $6 \mathrm{~F}$. Além disso, a criança 1F não reconheceu o significado da palavra camisador (pessoa que faz, vende, fabrica camisa). A pseudopalavra frutador (pessoa que vende, colhe, planta fruta) foi reconhecida por todos os sujeitos do Grupo 1.

Nos pseudovocábulos constituídos pelo sufixo -eiro, num total de 28 possibilidades de reconhecimento (16 para FE1 e 12 para FE2), apenas 3 palavras não foram identificadas pelos informantes. Assim, observamos que, com exceção da informante $1 \mathrm{~F}$, que não interpretou o significado do pseudovocábulo batereiro (pessoa que bate, baterista), e do sujeito $8 \mathrm{M}$, que não interpretou as palavras futeboleiro (pessoa que joga futebol) e lavareiro (pessoa que lava), todas as crianças do Grupo I alcançaram o primeiro objetivo da tarefa, interpretando o significado do sufixo agentivo -eiro em todas as pseudopalavras do instrumento. 
No que diz respeito às pseudopalavras compostas pelo sufixo -ista, num total de 28 possibilidades de reconhecimento (16 para FE1 e 12 para FE2), os dados apontaram que as crianças da FE1 apresentaram dificuldade de interpretar as palavras inventadas por um morfema base + sufixo agentivo -ista, sendo que das 16 possibilidades apenas 8 vocábulos foram reconhecidos da forma esperada. As crianças $1 \mathrm{~F}$ e $3 \mathrm{M}$ não reconheceram as seguintes palavras: jardinista (pessoa que cuida, planta, colhe, rega as plantas), e quadrista (pessoa que vende, fabrica, pinta, desenha quadros). 0 vocábulo arvorista (pessoa que planta, cuida das árvores) não foi interpretado pelos informantes $1 \mathrm{~F}, 2 \mathrm{~F}$ e $3 \mathrm{M}$, enquanto a palavra moranguista (pessoa que planta, colhe, vende cuida de morangos) foi reconhecida por todos os sujeitos. De acordo com o Quadro 1, concluímos que as crianças da FE2 - Grupo 1 interpretaram os pseudovocábulos de forma bastante significativa.

Com relação à pergunta sobre qual era a parte comum nas palavras, verificamos que apenas a informante $6 \mathrm{~F}$ identificou que os sufixos -(d)or, -eiro e -ista eram os morfemas que estavam adjungidos aos radicais dos vocábulos que compuseram a Tarefa de Reconhecimento de Pseudovocábulos.

No que diz respeito à localização do afixo, a maioria das crianças, exceto as informantes $1 \mathrm{~F}$ no sufixo -(d)or e $2 \mathrm{~F}$ e $3 \mathrm{~F}$ no sufixo -ista, apontaram que os sufixos se encontram no final dos pseudovocábulos.

\subsection{Reconhecimento dos sufixos -or, -eiro, -ista - Grupo 2}

Os resultados referentes à aplicação da Tarefa de Reconhecimento de Pseudovocábulos (Sufixos -or, -eiro, -ista) no Grupo 2 (FE3 e FE4) estão expostos no Quadro 2.

Conforme os resultados do Quadro 2, os informantes que integraram o Grupo 2 foram capazes de interpretar o significado das pseudopalavras formadas por um morfema-base + sufixos agentivos -or, -eiro, -ista. Esse dado indica que os sujeitos reconhecem qual é a função que exerce o sufixo agentivo quando associado a um morfema lexical, mesmo que essa junção forme vocábulos que não pertencem ao léxico do $\mathrm{PB}$.

Quadro 2 - Resultados da aplicação da Tarefa de Reconhecimento Pseudovocábulos (Sufixos -or, -eiro, -ista) - Grupo 2

\begin{tabular}{|c|c|c|c|c|c|c|c|c|c|c|c|c|c|c|c|c|c|c|c|c|c|c|}
\hline \multicolumn{23}{|c|}{ GRLP0? } \\
\hline Strtios & \multicolumn{11}{|c|}{ FE3 } & \multicolumn{11}{|c|}{ FE4 } \\
\hline $\begin{array}{l}.0 R \\
. E I R O\end{array}$ & \multicolumn{4}{|c|}{ 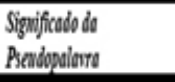 } & \multicolumn{4}{|c|}{\begin{tabular}{|l} 
Parte comm nas \\
palogros
\end{tabular}} & \multicolumn{3}{|c|}{ Localitagio do oficio } & \multicolumn{4}{|c|}{ 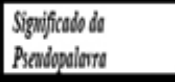 } & \multicolumn{4}{|c|}{ 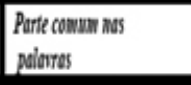 } & \multicolumn{3}{|l|}{$\begin{array}{l}\text { Localizycio } \\
\text { boofivio }\end{array}$} \\
\hline - ISIA & $\begin{array}{l}9 \\
\mathrm{~B}\end{array}$ & $\begin{array}{l}10 \\
\mathrm{~F}\end{array}$ & $\begin{array}{l}11 \\
\text { MI }\end{array}$ & \begin{tabular}{|l}
12 \\
M
\end{tabular} & F & $\begin{array}{l}10 \\
\mathrm{~F}\end{array}$ & $\begin{array}{l}\text { II } \\
\text { M }\end{array}$ & {$\left[\begin{array}{l}12 \\
M\end{array}\right.$} & \begin{tabular}{l|l}
9 & 1 \\
$\mathrm{~F}$ & $\mathrm{~B}$ \\
\end{tabular} & $\begin{array}{ll}11 \\
M\end{array}$ & $\begin{array}{l}12 \\
\text { IV }\end{array}$ & $\begin{array}{l}13 \\
\mathrm{~F}\end{array}$ & $\begin{array}{l}14 \\
\mathrm{E}\end{array}$ & $\begin{array}{l}15 \\
\text { M } \\
\end{array}$ & $\begin{array}{l}16 \\
M\end{array}$ & $\begin{array}{l}13 \\
\mathrm{~F}\end{array}$ & $\begin{array}{l}14 \\
5\end{array}$ & \begin{tabular}{|l|}
5 \\
MI \\
\end{tabular} & $\begin{array}{l}16 \\
M \\
\end{array}$ & \begin{tabular}{|l|l|}
13 & 14 \\
$\mathrm{~F}$ & $\mathrm{~F}$ \\
\end{tabular} & $\begin{array}{l}15 \\
M\end{array}$ & $\begin{array}{l}16 \\
M\end{array}$ \\
\hline Bencosior & $X$ & $X$ & $X$ & $X$ & $\pi$ & $d x$ & 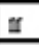 & III & \begin{tabular}{l|l}
$F$ & $F$ \\
\end{tabular} & 1 & $\mathrm{~F}$ & $\mathrm{X}$ & $X$ & $X$ & $X$ & $d x$ & $d x$ & $a$ & $d x$ & \begin{tabular}{|l|l|}
$\mathrm{F}$ & $\mathrm{F}$ \\
\end{tabular} & $\mathrm{F}$ & $\mathrm{F}$ \\
\hline Intasor & $\mathrm{X}$ & $X$ & $X$ & $X$ & & & & & & & & $\mathrm{X}$ & $X$ & $X$ & $\mathrm{X}$ & & & & & & & \\
\hline CarisodioR & $X$ & $X$ & $X$ & $\mathrm{X}$ & & & & & & & & $\mathrm{X}$ & $X$ & $X$ & $\mathrm{X}$ & & & & & & & \\
\hline Pipaior & $X$ & $\mathrm{X}$ & $X$ & $\mathrm{X}$ & & & & & & & & $\mathrm{X}$ & $X$ & $X$ & $\mathrm{X}$ & & & & & & & \\
\hline TelfonEIRA & $X$ & $X$ & $X$ & $X$ & 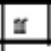 & 10 & 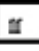 & II & \begin{tabular}{l|l}
$F$ & $F$ \\
\end{tabular} & $\mathrm{~F}$ & $\mathrm{~F}$ & $X$ & $X$ & $X$ & $X$ & 10 & erio & 10 & 10 & \begin{tabular}{|l|l|}
$\mathrm{F}$ & $\mathrm{F}$ \\
\end{tabular} & $\mathrm{F}$ & $\mathrm{F}$ \\
\hline FutableIRO & $X$ & $X$ & $X$ & $X$ & & & & & & & & $X$ & $X$ & $X$ & $X$ & & & & & & & \\
\hline LARGEIRO & X & $X$ & $X$ & $X$ & & & & & & & & $\mathrm{X}$ & $X$ & $X$ & $X$ & & & & & & & \\
\hline BataEIRO & $\mathbb{I}$ & $X$ & $X$ & $X$ & & & & & & & & $\mathrm{X}$ & $X$ & $X$ & $X$ & & & & & & & \\
\hline dinorISTA & $\mathrm{X}$ & $X$ & $X$ & $X$ & 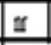 & ti & is & $\underline{I I}$ & \begin{tabular}{l|l}
$F$ & $F$ \\
\end{tabular} & F & $F$ & $X$ & $X$ & $X$ & $X$ & tis & ista & $t$ & 束 & \begin{tabular}{|l|l|}
$F$ & $F$ \\
\end{tabular} & $F$ & $F$ \\
\hline JarinilSLA & X & $X$ & $X$ & X & & & & & & & & $X$ & $X$ & X & X & & & & & & & \\
\hline YorangilSIA & 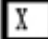 & $X$ & $X$ & X & & & & & & & & $\mathrm{X}$ & $X$ & X & $\mathrm{X}$ & & & & & & & \\
\hline QuatriSLA & $\mathrm{X}$ & $\mathrm{X}$ & III & $\mathrm{X}$ & & & & & & & & $\mathrm{X}$ & $X$ & III & $\mathrm{X}$ & & & & & & & \\
\hline
\end{tabular}

Fonte: As autoras.

Os dados apontaram que todas as crianças do Grupo 2 foram capazes de interpretar as 32 possibilidades de reconhecimento (16 para FE3 e 16 para FE4) das pseudopalavras formadas por um morfema-base + sufixo agentivoor. No que diz respeito aos pseudovocábulos compostos por um morfemabase + sufixo agentivo -eiro, num total de 32 possibilidades (16 para FE3 e 12 para FE4), somente a palavra batereiro não foi interpretada pela informante 9F. Já as pseudopalavras formadas por um morfema-base + sufixo agentivo 
-ista, num total de 32 possibilidades (16 para FE3 e 16 para FE4), apenas as crianças $11 \mathrm{M}$ e $15 \mathrm{M}$ - Grupo 2 - não reconheceram o significado de um pseudovocábulo: quadrista.

A partir do Quadro 2, verificamos que os informantes do Grupo 2 - FE3 e FE4 - interpretaram os pseudovocábulos que compuseram essa atividade de forma significativa, reconhecendo, assim, que os sufixos -or, -eiro, -ista, ao serem adjungidos a um morfema lexical, formam vocábulos com significado de agente.

Com relação à pergunta feita às crianças sobre qual era a parte comum nos vocábulos, observamos que os informantes 10F, 13F, 14F, 15M e 16M reconheceram que as pseudopalavras eram formadas por um morfema-base + sufixo -(d)or. 0 reconhecimento do sufixo agentivo -eiro foi segmentado da forma "padrão" apenas pela criança $14 \mathrm{~F}$, enquanto que os informantes $10 \mathrm{~F}$, $13 \mathrm{~F}, 15 \mathrm{M}$ e $16 \mathrm{M}$ segmentaram a sílaba ro, em lugar do sufixo -eiro.

No que se refere ao questionamento que pediu que os sujeitos indicassem qual era o "pedacinho" igual em todos os vocábulos formados por um morfema-base + sufixo -ista, verificamos que as crianças $10 \mathrm{~F}, 13 \mathrm{~F}$ e 15M segmentaram apenas a sílaba ta. Já o informante 16M segmentou a sequência sta e apenas os sujeitos $11 \mathrm{M}$ e $14 \mathrm{~F}$ segmentaram o morfema em sua integralidade -ista.

Analisando os dados do Grupo 2, observamos que a maioria das crianças participantes desse grupo não apresentou dificuldade de segmentar as pseudopalavras, mesmo que essa segmentação não fosse apresentada pelos informantes em unidades morfológicas propriamente, mas em sílabas, como já mencionado anteriormente. A respeito da localização do afixo, os sujeitos do Grupo 2 apontaram que os morfemas agentivos -or, -eiro, -ista se encontram posicionados na borda direita das palavras.

Considerando os dados dos Grupos 1 e 2, constatamos que a maioria dos sujeitos participantes deste trabalho não apresentaram dificuldade de interpretar o significado dos pseudovocábulos. Já com referência à segmentação dos sufixos agentivos -or, -eiro, -ista, essa capacidade parece expandir-se gradativamente: conforme mostram os resultados, há indícios de um aumento dessa habilidade a partir do desenvolvimento linguístico e escolar das crianças. Além disso, no que diz respeito à posição do afixo nas palavras, as crianças, com algumas exceções, identificaram que os morfemas sufixais se localizam no final das palavras.

\subsection{Reconhecimento dos prefixos des-e re--Grupo 1}

Os dados referentes à aplicação da Tarefa de Reconhecimento de Pseudovocábulos (prefixos des-, re-) no Grupo 1 (FE1 e FE2) são apresentados no Quadro 3.

Quadro 3 - Resultados da aplicação da Tarefa de Reconhecimento Pseudovocábulos (Prefixos des- e re-) - Grupo 1

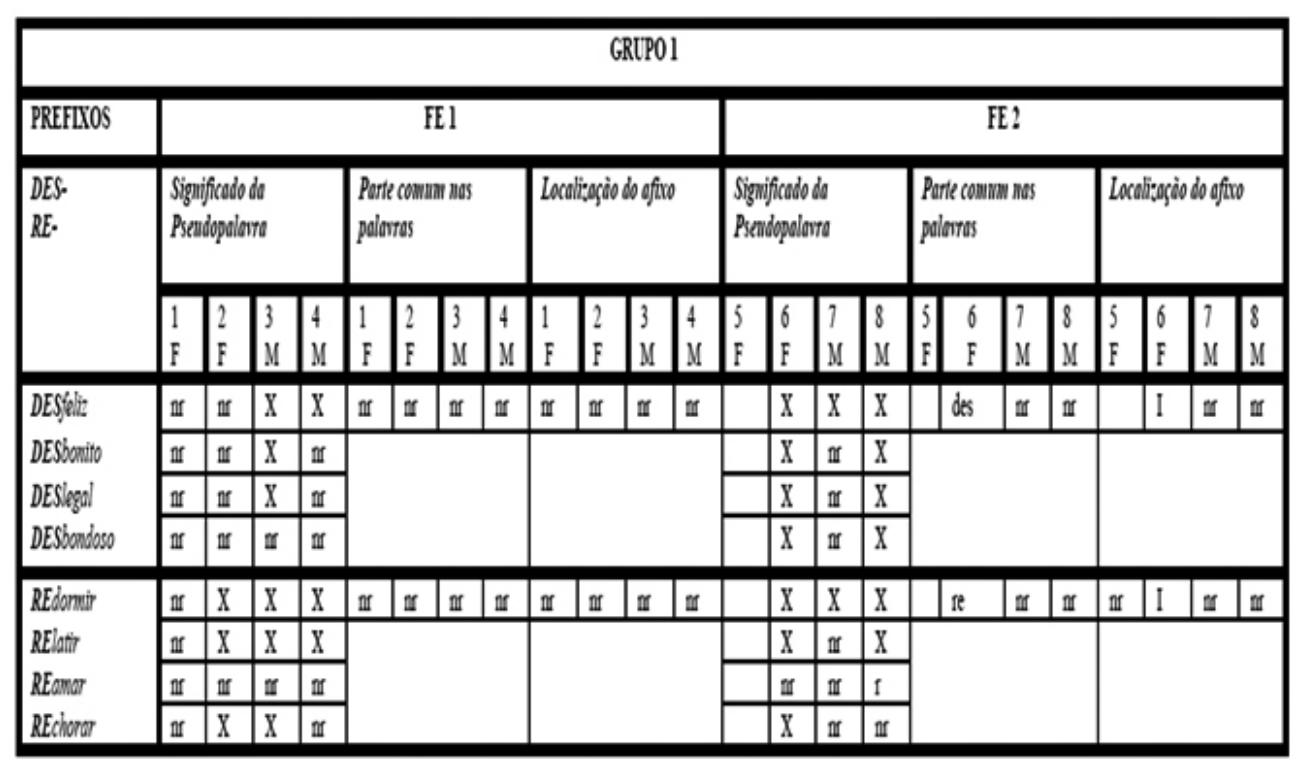

Fonte: as autoras. 
Segundo os dados do Quadro 3, os sujeitos do Grupo 1 mostraram dificuldade de reconhecerem as pseudopalavras que foram derivadas pelo prefixo des- (sentido de negação, oposição) e re- (sentido de repetição) somados ao morfema lexical. Os pseudovocábulos que compuseram esta tarefa foram formados primeiramente pelo prefixo des- + morfema-base: desfeliz (não estar feliz, estar triste); desbonito (não é bonito, é feio); deslegal (não é legal, é chato); e desbondoso (não é bondosos, é mau). As palavras compostas pelo prefixo re- + morfema-base foram: redormir (dormir de novo); relatir (latir de novo); reamar (amar de novo); e rechorar (chorar de novo).

Nas pseudopalavras constituídas pelo prefixo des-, num total de 28 possibilidades de reconhecimento (16 para FE1 e 12 para FE2), verificamos que os sujeitos reconheceram apenas 13 pseudovocábulos formados pelo prefixo + morfema-base. Constatamos que o informante $3 \mathrm{M}$ interpretou três pseudopalavras da tarefa, sendo a palavra desbondoso a única não reconhecida pela criança. 0 sujeito $4 \mathrm{M}$ reconheceu apenas o pseudovocábulo desfeliz. Já as crianças 6F e 8M da FE2 atingiram o objetivo esperado, interpretando o significado das palavras formadas pelo prefixo des- + morfema lexical. $\mathrm{O}$ informante 7M reconheceu o significado apenas da palavra desfeliz.

Cabe destacar que as crianças $1 \mathrm{~F}$ e $2 \mathrm{~F}$ (FE1) apresentaram um comportamento diferente ao serem perguntadas sobre o significado das pseudopalavras: enquanto os outros informantes não tinham nenhuma resposta ou apenas diziam não saber responder, as informantes apenas reproduziram o morfema lexical, indicando-o como resposta correta, mesmo depois de serem repetidamente questionadas pela pesquisadora se a palavra deslegal é o mesmo que legal; a presença do prefixo parecia passar despercebida pela criança. A palavra deslegal foi tomada como uma variante da palavra legal.
No que se refere aos dados do prefixo re-, verificamos que, das 28 possibilidades de reconhecimento das palavras derivadas com o morfema re-, as crianças do Grupo I identificaram o significado de 14 palavras. Os resultados indicaram que a criança $1 \mathrm{~F}$ não reconheceu o significado de nenhum dos pseudovocábulos da tarefa. Já os informantes $2 \mathrm{~F}, 3 \mathrm{M}$ e $6 \mathrm{~F}$ apenas não reconheceram a pseudopalavra reamar, enquanto as crianças $4 \mathrm{M}$ e $8 \mathrm{M}$ não identificaram as palavras reamar e rechorar. 0 sujeito $7 \mathrm{M}$ apenas reconheceu o significado da palavra redormir.

Com relação à solicitação de que os informantes indicassem o que todas as palavras tinham em comum, apenas a menina $6 \mathrm{~F}$ apontou que os prefixos des- $e$ re- eram os "pedacinhos" iguais em todos os vocábulos. Os outros sujeitos que compuseram o Grupo I não souberam responder essa questão.

No que se refere à pergunta sobre a posição dos prefixos des- $e$ re nos pseudovocábulos, constatamos que apenas a informante 6F indicou que o morfema se localiza no início das palavras.

\subsection{Reconhecimento dos prefixos des- e re- - Grupo 2}

Os resultados referentes à aplicação da Tarefa de Reconhecimento de Pseudovocábulos (prefixos des-, re-) no Grupo 2 (FE3 e FE4) estão expostos no Quadro 4, adiante.

Os dados do Quadro 4 indicaram que todos os informantes do Grupo 2 (FE3 e FE4) identificaram o significado das palavras formadas pelo prefixo des- + um morfema base, indicando que reconheceram a função que esse morfema exerce ao ser anteposto a um morfema lexical, mesmo que a formação resulte em vocábulos que não fazem parte do léxico da língua.

No que se refere à pergunta sobre qual era a parte comum em todas as pseudopalavras, as crianças $10 \mathrm{~F}, 12 \mathrm{M}$ e $14 \mathrm{~F}$ indicaram o prefixo como uma sílaba $\mathrm{CV}(\mathrm{de})$, retirando a coda silábica constituída pela fricativa /s/ da estrutura do prefixo. Já os informantes 11M,13F, 15M e 16M apontaram 
o prefixo des-, segmentando-o corretamente. Apenas a menina $9 \mathrm{~F}$ não identificou a parte igual em todas as palavras.

Quadro 4 - Resultados da aplicação da Tarefa de Reconhecimento Pseudovocábulos (Prefixos des- e re-) - Grupo 2

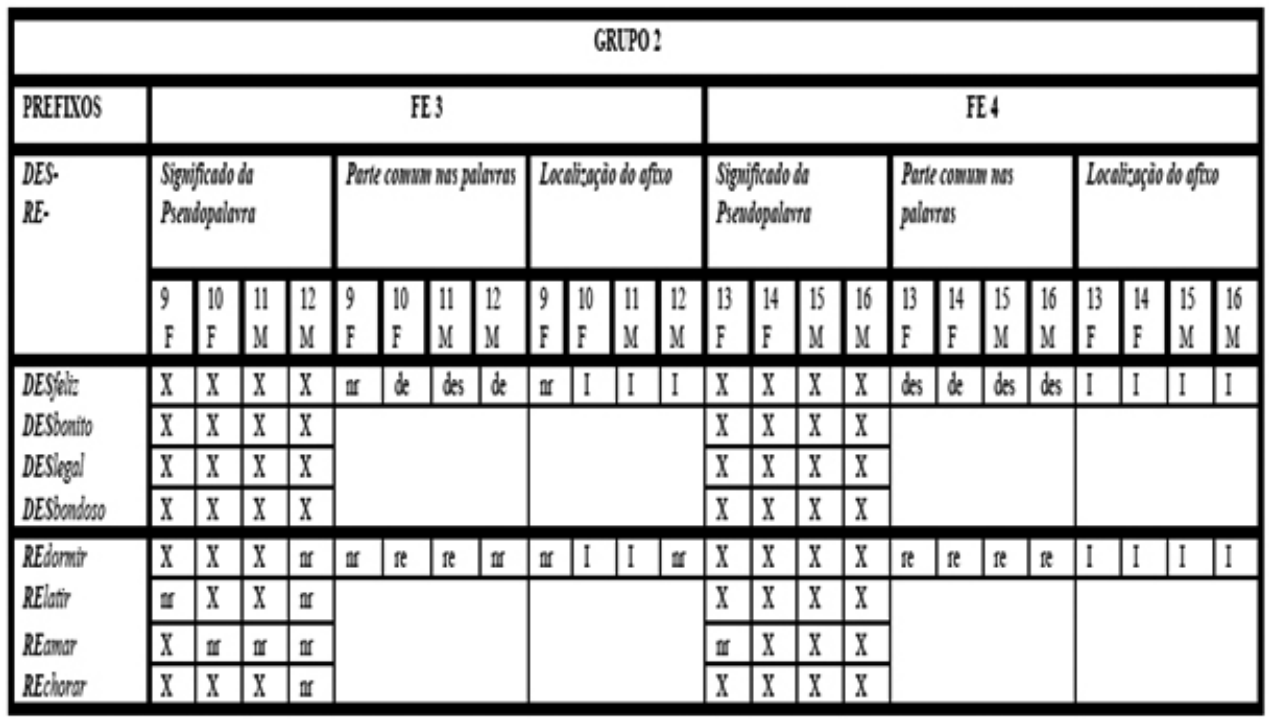

Fonte: as autoras.

Os dados referentes ao prefixo re- apontaram que as crianças do Grupo 2 (FE3 e FE4) reconheceram o significado de alguns dos pseuvocábulos que fizeram parte da tarefa, indicando que a derivação com o prefixo reparece ser mais complexa do que a derivação como prefixo des-. Constatamos que, nas palavras formadas pelo sufixo des- + morfema lexical, todas as pseudopalavras da tarefa foram interpretadas pelos informantes, no entanto, com o prefixo re-, houve 24 reconhecimentos em 32 possibilidades.

Ressaltamos que na FE3, de 16 possibilidades, foram reconhecidas apenas 9 palavras formadas pelo prefixo re- + morfema-base. Das palavras não reconhecidas, a criança $9 \mathrm{~F}$ não interpretou o significado da palavra relatir e os informantes $10 \mathrm{~F}$ e $11 \mathrm{M}$ não definiram o significado de reamar. Salientamos que a criança 12M não interpretou o significado de nenhuma das palavras inventadas com o prefixo re-.

$\mathrm{Na} F E 4$ somente o vocábulo reamar não foi interpretado pelo sujeito $13 \mathrm{~F}$, indicando, assim, que as crianças dessa FE apresentaram a capacidade de segmentar as palavras em morfemas e de refletir sobre a estrutura interna de palavras.

Os informantes do Grupo 2, em sua grande maioria, identificaram que o prefixo re- era o "pedacinho" igual existente em todas as palavras inventadas. Apenas as crianças 9F e 12M não conseguiram identificá-lo.

No que diz respeito à localização dos prefixos des- e re-, as crianças do Grupo 2, exceto os informantes 9F (des- e re-) e 12M ( $r e$-), indicaram que esses morfemas se encontravam na borda esquerda das palavras.

Apesar de os sujeitos da FE 1 terem reconhecido o prefixo re- mais do que o prefixo des-, constatamos que o reconhecimento desse morfema se manteve estável, de modo geral, até a FE 3, mas sempre com um sucesso menor do que o obtido em relação ao prefixo des-; portanto, não houve um crescimento significativo no reconhecimento do prefixo re-. Analisando os resultados obtidos nos Grupos 1 e 2, compreendemos que o reconhecimento do afixo re-se deu por grande parte dos informantes da FE 4.

No que tange à segmentação do prefixo re-, essa habilidade parece desenvolver-se gradativamente, aumentando com o desenvolvimento da criança, conforme indicam os resultados do estudo. Merece destaque o fato de que, quando o prefixo $r e$ - foi segmentado por informantes das diferentes FEs, essa segmentação foi adequada. 0 resultado parece confirmar que o conhecimento fonológico, especialmente da unidade sílaba, parece estar na base das segmentações: pelo fato de o prefixo re-ser constituído por uma sílaba CV, sua segmentação não apresentou dificuldade para as crianças. 
Todos os resultados obtidos mostram-se sumarizados nas considerações finais deste estudo.

\section{Considerações finais}

A pesquisa, com foco no desenvolvimento da Consciência Morfológica, centrou-se na análise dessa capacidade de processamento linguístico em crianças falantes nativas do PB, pertencentes a dois grupos (divididos em quatro faixas etárias), sendo o primeiro formado por crianças não alfabetizadas, com idades entre 4 e 5 anos, e o segundo, constituído por crianças em processo de alfabetização, com as idades entre 6 e 7 anos.

Neste estudo, a Consciência Morfológica foi avaliada por meio de uma tarefa, denominada Tarefa de Reconhecimento de Pseudovocábulos, que tinha como objetivo verificar o desenvolvimento da Consciência Morfológica, observando como se dá o processamento de pseudovocábulos. Os morfemas da língua foco da pesquisa foram os sufixos derivacionais -or, -eiro e -ista e os prefixos des- e re-.

Mesmo que não se discuta o momento da emergência da Consciência Morfológica, fato sobre o qual ainda não há consenso na literatura, o presente estudo permite afirmarmos que o desenvolvimento dessa habilidade é progressivo e, de acordo com BORGES (2015), se estabelece em níveis, quais sejam:

(a) 1o nível - nível em que há o reconhecimento de que palavras primitivas e derivadas são diferentes;

(b) 2º nível - nível no qual há o reconhecimento da posição de um afixo na palavra;

(c) 3oo nível - nível em que há a segmentação da palavra em morfemas.

O 3o nível pode ser subdividido em dois: (3a) quando há a segmentação de partes do morfema (nesse subnível, a segmentação do morfema parece ser realizada com a interferência de unidades da fonologia, como, por exemplo, sílaba e segmento); e (3b) quando há a segmentação do morfema propriamente dito.

De acordo com os dados, os níveis estão presentes já nos anos iniciais de desenvolvimento da criança, como na FE 1 deste estudo. No que diz respeito à interpretação que os informantes faziam dos pseudovocábulos, em ambos os grupos, 1 e 2, observamos que a maioria das crianças foi capaz de identificar o significado das pseudopalavras formadas por um sufixo agentivo somado a um morfema base, como em frutador, telefoneira e moranguista (reconhecidos na integralidade). Tal fato indica a capacidade de reflexão sobre os morfemas que integram a gramática da língua, uma vez que a Tarefa de Reconhecimento de Pseudovocábulos tinha como objetivo evidenciar a capacidade das crianças de manipularem os morfemas, exigindo, ao longo da aplicação, a utilização e/ou reconhecimento de afixo - sufixos e prefixos - em palavras não existentes na língua.

Sobre o reconhecimento da localização do afixo na palavra, os dados mostraram que o Grupo 1 não apresentou grandes dificuldades em reconhecer a posição dos sufixos, assim como o Grupo 2; neste grupo, todos os informantes atingiram o que se propunha. Diferentemente, no tocante aos prefixos, verificamos que a grande maioria das crianças que fazem parte do Grupo 1 mostrou dificuldade em apontar a sua posição nas pseudopalavras. O Grupo 2 apontou um resultado satisfatório. Essa diferença entre os dois grupos evidencia a gradação que caracteriza a consciência dos morfemas da língua e a influência que o processo de alfabetização pode ter nessa capacidade linguística, já que as crianças do Grupo 2, que estão em processo de alfabetização, mostraram sempre melhor desempenho na tarefa. Também essa diferença entre os dois grupos indica a maior complexidade que os prefixos mostram ao serem comparados aos sufixos. 
A respeito do $3^{\circ}$ nível de desenvolvimento da Consciência Morfológica, referente à segmentação da palavra em morfemas, os resultados relativos ao sufixo mostraram que, no Grupo 1, a grande maioria dos informantes não foi capaz de segmentar as palavras em morfemas, com exceção da criança 6F, que realizou a proposta adequadamente, segmentando a palavra no nível dos morfemas. Já no Grupo 2, os resultados se mostraram satisfatórios, uma vez que, na FE 4, de 12 possibilidades, foram verificadas 12 realizações nos 2 subníveis de Consciência Morfológica: quanto à segmentação de partes do morfema, foram computadas 6 realizações; e quanto à segmentação do morfema propriamente dito, observamos 6 reconhecimentos. Diferentemente, na FE 3 poucos foram os reconhecimentos dos segmentos que compuseram as pseudopalavras utilizadas na tarefa proposta. Sobre os prefixos, os resultados mostraram que a maioria dos informantes do Grupo 2 conseguiu identificar a parte comum entre as palavras, segmentando-as em morfemas; novamente o efeito da alfabetização pode ser responsável por esse resultado.

De modo especial, os dados referentes à Tarefa de Reconhecimento de Pseudovocábulos indicaram que a consciência da derivação sufixal parece ser adquirida mais precocemente do que a da derivação prefixal no processo de aquisição da Morfologia do PB. Ademais, os dados parecem apontar uma diferença, quanto a níveis de complexidade ou de marcação, entre os prefixos e os sufixos da língua: o sufixo -or parece menos marcado do que o sufixo -ista no reconhecimento de palavras formadas por morfema base somado ao sufixo agentivo. Os dados também apontaram que o prefixo des- parece ser menos marcado do que o prefixo re- na formação de nomes do PB.

Com os resultados obtidos, o estudo buscou descrever e analisar a Consciência Morfológica em crianças não alfabetizadas e em processo de alfabetização, o que foi operacionalizado pela análise de dados de reconhecimento de morfemas derivacionais do $\mathrm{PB}$, tendo como foco os sufixos -eiro, -ista, -or e os prefixos -des e -re.

Ao final, salientamos a contribuição desta pesquisa ao somar-se aos ainda escassos trabalhos sobre o desenvolvimento da Consciência Morfológica, principalmente sobre a aquisição do PB. Ressaltamos, ainda, a particularidade de a tarefa aplicada neste estudo ter sido elaborada especificamente para a presente pesquisa, embasando-se em trabalhos existentes na literatura. Acreditamos que a atividade possa contribuir significativamente para outras pesquisas da área, já que delimita e analisa o reconhecimento dos morfemas.

\section{Referências}

BORGES, V. P. Consciência morfológica em crianças não alfabetizadas e em processo de alfabetização: produção e reconhecimento de morfemas. Dissertação (Mestrado) UCPel, Pelotas, 2015.

BRYANT, P.; DEVINE, M.; LEDWARD, A.; NUNES, T. Spelling with apostrophes and understanding possession. British Journal of Educational Psychology, v. 67, p. 91-110, 1997. https://doi.org/10.1111/j.2044-8279.1997.tb01229.x

BRYANT, P.; NUNES, T.; AIDINIS, A. Different morphemes, same spelling problems: crosslinguistic developmental studies. In: HARRIS, M.; HATANO, G. (Ed.). Learning to read and write: a cross-linguistic perspective. Cambridge: Cambridge University Press. 1999. p. $112-133$.

BRYANT, P.; NUNES, T. Morphology and spelling. In: NUNES, T. (Ed.). Handbook of children's literacy. Dordrecht: Kluwer Academic Publishers. 2003. p. 162-214.

CARLISLE, J. F. Knowledge of derivational morphology and spelling ability in fourth, sixth and eighth graders. Applied Psycholinguistics, v. 9, p. 247-266. 1988. https://doi. org/10.1017/S0142716400007839

CARLISLE, J. F.; NOMANBHOY, D. Phonological and morphological awareness in first graders. Applied Psycholinguistics, v. 14, p. 177-195, 1993. https://doi.org/10.1017/ S0142716400009541 
CARLISLE, J. F. Morphological awareness and early reading achievement. In: L. FELDMAN (Org.). Morphological aspects of language processing. Hillsdale: Lawrence Erlbaum Associates, 1995. p. 189-211.

CARLISLE, J. F. Awareness of the structure and meaning of morphologically complex words: Impact on reading. Reading and Writing: An Interdisciplinary Journal, v. 12, p. 169-190, 2000. https://doi.org/10.1023/A:1008131926604

FIGUEIRA, R. A. Aquisição dos Verbos Prefixados por DES- em Português. Revista Palavra, Campinas, v. 5, parte IV, p. 190-211, 1999.

LIMA, P. A. N. de. Aquisição da morfologia do português brasileiro por crianças de dois a sete anos de idade: afixos e compostos. Dissertação (Mestrado) - UFRGS, Porto Alegre, 2006.

LORANDI, A. Formas morfológicas variantes na gramática infantil: um estudo à luz da Teoria da Otimidade. Dissertação (Mestrado) - PUCRS, Porto Alegre: 2006.

MACHADO, M. J. M. da C. Implicações da consciência morfológica no desenvolvimento da escrita. Dissertação (Mestrado) - Instituto Politécnico de Lisboa, Lisboa, 2011.

MELO, K. Compreendendo as relações entre consciência gramatical e habilidade de leitura e escrita: um estudo de intervenção. Tese (Doutorado) - Universidade Federal de Pernambuco, Recife, 2002.

NUNES, T.; BRYANT, P.;; BINDMAN, M. Morphological spelling strategies: Developmental stages and processes. Developmental Psychology, v. 33, p. 637-649, 1997a. https://doi. org/10.1037/0012-1649.33.4.637

NUNES, T.; BRYANT, P.; BINDMAN, M. Learning to spell regular and irregular verbs. Reading and Writing: An Interdisciplinary Journal, v. 9, n. 5-6, p. 427-449, 1997b. https://doi.org/10.1023/A:1007951213624

NUNES, T.; BRYANT, P.; BINDMAN, M. Spelling and grammar: The necsed move. In: PERFETI, C.; RIEBEN, L.; FAYOL, M. (Ed.). Learning to spell: research, theory and practice across languages. 1997c. p. 151-170.

NUNES, T. Developing children's minds through literacy and numeracy. University of London: Institute of Education, 1998.

ROSA, J. Morphological awareness and spelling development. Unpublished PhD Thesis Department of Psychology, Oxford Brookes University, UK. 2003.
RUBIN, H. Morphological knowledge and early writing ability. Language and Speech, v. 31, p. 337-355, 1988. https://doi.org/10.1177/002383098803100403

SEIXAS, M. C. P. $O$ desenvolvimento da consciência morfológica em crianças de 5 anos Dissertação (Mestrado) - Ualg, Faro, 2007.

Recebido em: 25/01/2017 Aprovado em: 22/07/2017 